Fetal Diagnosis and Therapy
Fetal Diagn Ther 2013;33:8-15

DOI: $\underline{10.1159 / 000341264}$
Received: April 25, 2012

Accepted after revision: June 21, 2012

Published online: August 16, 2012

\title{
Competing Risks Model in Early Screening for Preeclampsia by Biophysical and Biochemical Markers
}

\author{
Ranjit Akolekar ${ }^{b, d}$ Argyro Syngelaki $^{\text {b-d }}$ Leona Poon ${ }^{b}$ David Wright ${ }^{a}$ \\ Kypros H. Nicolaides ${ }^{b, c}$ \\ ${ }^{a}$ School of Computing and Mathematics, Plymouth University, Plymouth, ${ }^{b}$ Harris Birthright Research Centre of \\ Fetal Medicine, King's College Hospital, and 'Department of Fetal Medicine, University College Hospital, London, \\ and d Department of Fetal Medicine, Medway Maritime Hospital, Gillingham, UK
}

\section{Key Words}

First-trimester screening • Preeclampsia • Uterine artery Doppler $\cdot$ Mean arterial pressure $\cdot$ Placental growth factor • Pyramid of pregnancy care

\section{Abstract \\ Objective: To develop models for prediction of preeclamp- sia (PE) based on maternal characteristics, biophysical and biochemical markers at 11-13 weeks' gestation in which the gestation at the time of delivery for PE is treated as a con- tinuous variable. Methods: This was a screening study of sin- gleton pregnancies at 11-13 weeks including 1,426 (2.4\%) that subsequently developed PE and 57,458 that were unaf- fected by PE. We developed a survival time model for the time of delivery for PE in which Bayes' theorem was used to combine the prior information from maternal characteristics with uterine artery pulsatility index (PI), mean arterial pres- sure (MAP), serum pregnancy-associated plasma protein- $A$ (PAPP-A) and placental growth factor (PLGF) multiple of the median (MoM) values. Results: In pregnancies with $\mathrm{PE}$, there was a linear correlation between MoM values of uterine ar- tery PI, MAP, PAPP-A and PLGF with gestational age at deliv-}

ery and therefore the deviation from normal was greater for early than late PE for all four biomarkers. Screening by maternal characteristics, biophysical and biochemical markers detected $96 \%$ of cases of PE requiring delivery before 34 weeks and $54 \%$ of all cases of PE at a fixed false-positive rate of $10 \%$. Conclusions: A new model has been developed for effective first-trimester screening for PE.

Copyright @ 2012 S. Karger AG, Basel

\section{Introduction}

Preeclampsia (PE), which affects about $2 \%$ of pregnancies, is a major cause of maternal and perinatal morbidity and mortality [1-3]. The prevalence of PE can potentially be halved by a strategy of early identification of the high-risk group and the prophylactic use of aspirin [4-6]. Algorithms combining maternal demographic characteristics and medical and obstetric history with biophysical and biochemical markers at 11-13 weeks' gestation have been developed for the prediction of early or late PE on the basis of whether or not delivery occurs before 34 weeks' gestation $[7,8]$. However, we have re-

\section{KARGER \\ Fax +4161306 1234 \\ E-Mail karger@karger.ch}

www.karger.com (c) 2012 S. Karger AG, Basel

1015-3837/13/0331-0008\$38.00/0

Accessible online at:

www.karger.com/fdt
Prof. K.H. Nicolaides

Harris Birthright Research Centre for Fetal Medicine, King's College Hospital Denmark Hill

London SE5 9RS (UK)

Tel. +44 203299 8256, E-Mail kypros.nicolaides@ kcl.ac.uk 
cently proposed that early and late-PE are not two different diseases, but rather that $\mathrm{PE}$ is a spectrum disorder, the degree of which is reflected in both gestation at the time of delivery and the biomarker levels [9]. In the new approach to screening for PE, gestation at the time of delivery for PE is treated as a continuous rather than categorical variable. This approach, which is based on a survival time model, assumes that if the pregnancy was to continue indefinitely, all women would develop PE and whether they do so or not before a specified gestational age depends on a competition between delivery before or after development of PE. The effect of variables from maternal characteristics and history and biomarkers is to modify the mean of the distribution of gestational age at delivery with $\mathrm{PE}$, so that in pregnancies at low risk for PE the gestational age distribution is shifted to the right with the implication that in most pregnancies delivery will actually occur before the development of PE. In high-risk pregnancies the distribution is shifted to the left, and smaller mean gestational age increases the risk for PE.

In our first study we illustrated the new approach to screening by combining maternal characteristics and history with uterine artery pulsatility index (PI) and mean arterial pressure (MAP) at 11-13 weeks' gestation. The objective of this study is to extend the model by including the biochemical markers of serum pregnancy-associated plasma protein-A (PAPP-A) and placental growth factor (PLGF).

\section{Methods}

\section{Study Population}

The data for this study were derived from prospective screening for adverse obstetric outcomes in women attending for their routine first hospital visit in pregnancy at University College Hospital, King's College Hospital and Medway Maritime Hospital, UK. In this visit, which is held at $11^{+0}$ to $13^{+6}$ weeks of gestation, we record maternal characteristics and medical history and perform combined screening for aneuploidies by measurement of the fetal crown-rump length and nuchal translucency thickness, and maternal serum PAPP-A and free $\beta$-hCG $[10,11]$. The women were screened between March 2006 and September 2010. In the second part of the study period we also measured the maternal MAP by automated devices [12]; used transabdominal color Doppler ultrasound to visualize the left and right uterine artery, measure the PI in each vessel and calculate the mean PI [13]; and measured serum PLGF (DELFIA Xpress system, PerkinElmer Life and Analytical Sciences, Waltham, Mass., USA) [14]. Written informed consent was obtained from the women agreeing to participate in the study, which was approved by the appropriate Hospital Ethics Committee.
The inclusion criteria for this study on screening for PE were singleton pregnancy undergoing first-trimester combined screening for aneuploidy and subsequently delivering a phenotypically normal live birth or stillbirth at or after 24 weeks' gestation. We excluded pregnancies with aneuploidies and major fetal abnormalities, and those ending in termination, miscarriage or fetal death before 24 weeks of gestation and pregnancies delivering small for gestational age neonates in the absence of PE.

In this study we developed a model for predicting PE based on maternal characteristics in the study population. We then expanded this model for prediction of PE to include the addition of uterine artery PI, MAP, serum PAPP-A and PLGF.

\section{Maternal History and Characteristics}

Patients were asked to complete a questionnaire on maternal age, racial origin (Caucasian, Afro-Caribbean, South Asian, East Asian and mixed), method of conception (spontaneous or assisted conception requiring the use of ovulation drugs), cigarette smoking during pregnancy (yes or no), history of chronic hypertension (yes or no), history of type 1 or 2 diabetes mellitus (yes or no), history of systemic lupus erythematosus or antiphospholipid syndrome (yes or no), family history of PE in the mother of the patient (yes or no), and obstetric history including parity (parous or nulliparous if no previous pregnancies at or after 24 weeks) and previous pregnancy with $\mathrm{PE}$ (yes or no). The questionnaire was then reviewed by a doctor together with the patient and the maternal weight and height were measured.

\section{Outcome Measures}

Data on pregnancy outcome were collected from the hospital maternity records or the general medical practitioners of the women. The obstetric records of all women with pre-existing or pregnancy-associated hypertension were examined to determine if the condition was chronic hypertension, $\mathrm{PE}$ or nonproteinuric gestational hypertension.

The definition of PE was that of the International Society for the Study of Hypertension in Pregnancy [15]. The systolic blood pressure should be $140 \mathrm{~mm} \mathrm{Hg}$ or more and/or the diastolic blood pressure should be $90 \mathrm{~mm} \mathrm{Hg}$ or more on at least two occasions $4 \mathrm{~h}$ apart developing after 20 weeks of gestation in previously normotensive women, and there should be proteinuria of $300 \mathrm{mg}$ or more in $24 \mathrm{~h}$ or two readings of at least ++ on dipstick analysis of midstream or catheter urine specimens if no 24-hour collection is available. In PE superimposed on chronic hypertension, significant proteinuria (as defined above) should develop after 20 weeks of gestation in women with known chronic hypertension (history of hypertension before conception or the presence of hypertension at the booking visit before 20 weeks of gestation in the absence of trophoblastic disease). The definition of small for gestational age was birth weight below the 5 th percentile for gestational age of a reference range derived from our population [16].

\section{Statistical Analysis}

The new approach for early screening for PE was based on a survival time model for the time of delivery for PE. Bayes' theorem was used to combine the prior information from maternal characteristics with biomarker multiple of the median (MoM) values. We used a competing risk model $[9,17]$.

The distribution of gestational age at delivery with PE was defined by two components: firstly, the prior distribution based on 
Table 1. Fitted regression model for marker $\log _{10}$ MoM values on gestation at time of delivery for pregnancies with PE

\begin{tabular}{lrllrll}
\hline Marker & Intercept & SE & $\mathrm{p}$ & Slope & SE & $\mathrm{p}$ \\
\hline Uterine artery PI & 0.642102 & 0.038479 & $<0.0001$ & -0.015173 & 0.0010191 & $<0.0001$ \\
MAP & 0.114859 & 0.014798 & $<0.0001$ & -0.002115 & 0.0003917 & $<0.0001$ \\
PAPP-A & -0.656448 & 0.078707 & $<0.0001$ & 0.015555 & 0.0020837 & $<0.0001$ \\
PLGF & 0.861296 & 0.089182 & $<0.0001$ & 0.020221 & 0.0023705 & $<0.0001$ \\
\hline
\end{tabular}

Table 2. SD and correlations, with $95 \%$ confidence limits, for $\log _{10}$ MoM biomarker values

\begin{tabular}{llr}
\hline & No PE & PE \\
\hline SD uterine artery PI & $0.1242215(0.122254$ to 0.127840$)$ & $0.1409539(0.122250$ to 0.158148$)$ \\
SD MAP & $0.0386549(0.037002$ to 0.040257$)$ & $0.0426263(0.032693$ to 0.053506$)$ \\
SD PAPP-A & $0.2368016(0.229462$ to 0.237103$)$ & $0.2679589(0.252859$ to 0.285103$)$ \\
SD PLGF & $0.1764965(0.173864$ to 0.179168$)$ & $0.2165872(0.202972$ to 0.229780$)$ \\
Correlation uterine artery PI and MAP & $-0.0724816(-0.075278$ to -0.070882$)$ & $0.0093204(-0.004507$ to 0.014433$)$ \\
Correlation uterine artery PI and PAPP-A & $-0.156970(-0.177317$ to -0.145472$)$ & $-0.1766223(-0.256403$ to -0.099764$)$ \\
Correlation uterine artery PI and PLGF & $-0.1322802(-0.144440$ to -0.111484$)$ & $-0.2113414(-0.303681$ to -0.154827$)$ \\
Correlation MAP and PAPP-A & $-0.0069674(-0.020433$ to 0.011444$)$ & $0.0354576(-0.091128$ to 0.066178$)$ \\
Correlation MAP and PLGF & $-0.0346327(-0.052455$ to -0.018998$)$ & $0.0128895(-0.070326$ to 0.091987$)$ \\
Correlation PAPP-A and PLGF & $0.3009237(0.293361$ to 0.328260$)$ & $0.3543634(0.271487$ to 0.421228$)$ \\
\hline
\end{tabular}

maternal characteristics [9] and secondly, the distribution of MoM biomarker values with gestational age in pregnancies affected by PE. The values of uterine artery PI, MAP, PAPP-A and PLGF were $\log _{10}$-transformed to make their distribution Gaussian. Each measured value in the unaffected and PE pregnancies was expressed as a multiple of the normal median (MoM) after adjustment for those characteristics were found to provide a substantial contribution to the log-transformed value $[9,14,18]$. In the PE group, regression analysis was used to determine the relationship between $\log _{10}$ MoM marker values and gestational age at delivery.

In the estimation of performance of screening, the values of uterine artery PI, MAP, PAPP-A and PLGF in the whole screened population were simulated based on the mean and SD of the $\log _{10^{-}}$ transformed marker values in the unaffected and PE pregnancies. In the PE group, the mean and SD values used for simulation were specific for each gestational week at delivery, which were estimated from the regression analysis of the $\log _{10}$ MoM values of available data with gestational age at delivery.

\section{Results}

\section{Characteristics of the Study Population}

First-trimester combined screening for aneuploidies was carried out in 65,960 singleton pregnancies. We excluded 7,076 cases because they had missing outcome data $(n=2,133)$, the pregnancies resulted in miscarriage, termination or the birth of babies with major defects $(\mathrm{n}=$ $1,775)$ or the birth of small for gestational age neonates in the absence of PE $(n=3,168)$.

In the remaining 58,884 cases, there were $1,426(2.4 \%)$ that developed PE and 57,458 that were unaffected by PE. Serum PAPP-A was available in all cases. Uterine artery PI was available in 45,885 of the 58,884 pregnancies, including 1,245 (2.7\%) that developed PE; MAP was available in 35,215 of the 58,884 pregnancies, including 979 (2.8\%) that developed PE; and serum PLGF was available in 14,252 of the 58,884 pregnancies, including 385 (2.7\%) that developed PE.

The maternal characteristics and history in the PE and unaffected pregnancies in the screening population were previously reported [9]. In the PE group, compared to unaffected pregnancies, there was a higher mean maternal weight and prevalence of Afro-Caribbean racial origin, family and personal history of $\mathrm{PE}$, chronic hypertension, diabetes mellitus and systemic lupus erythematosus or antiphospholipid syndrome, and a lower prevalence of cigarette smokers. 
Fig. 1. Scatter diagram and regression line with 95\% confidence limits for the relationship between serum PAPP-A MoM and gestational age at delivery in pregnancies with PE.
Fig. 2. Scatter diagram and regression line with 95\% confidence limits for the relationship between serum PLGF MoM and gestational age at delivery in pregnancies with PE.

Early Prediction of PE
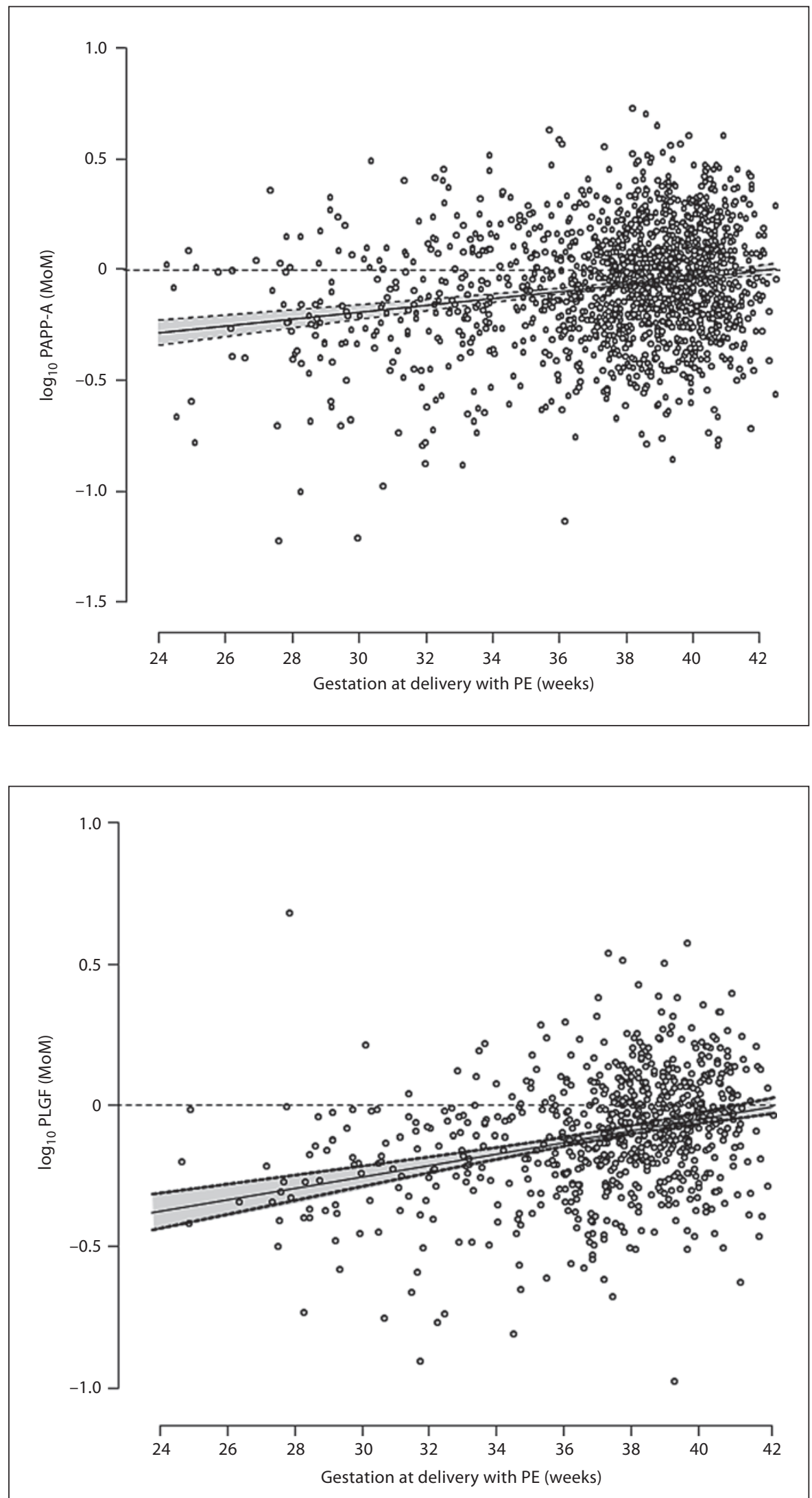

Fetal Diagn Ther 2013;33:8-15 
Table 3. Estimated detection rates of PE requiring delivery before 34, 37 and 42 weeks' gestation, at false-positive rates (FPR) of 5 and $10 \%$

\begin{tabular}{|c|c|c|c|c|c|c|c|}
\hline \multirow[t]{2}{*}{ Screening test } & \multirow[t]{2}{*}{$\begin{array}{l}\text { FPR } \\
\%\end{array}$} & \multicolumn{2}{|c|}{$\begin{array}{l}\mathrm{PE} \\
<34 \text { weeks }(\mathrm{n}=214)\end{array}$} & \multicolumn{2}{|c|}{$\begin{array}{l}\mathrm{PE} \\
<37 \text { weeks }(\mathrm{n}=568)\end{array}$} & \multicolumn{2}{|c|}{$\begin{array}{l}\mathrm{PE} \\
<42 \text { weeks }(\mathrm{n}=1,426)\end{array}$} \\
\hline & & $\begin{array}{l}\text { risk } \\
\text { cutoff }\end{array}$ & $\begin{array}{l}\text { detection } \\
\mathrm{n}(\%)\end{array}$ & $\begin{array}{l}\text { risk } \\
\text { cutoff }\end{array}$ & $\begin{array}{l}\text { detection } \\
\mathrm{n}(\%)\end{array}$ & $\begin{array}{l}\text { risk } \\
\text { cutoff }\end{array}$ & $\begin{array}{l}\text { detection } \\
\mathrm{n}(\%)\end{array}$ \\
\hline \multirow{2}{*}{ Maternal characteristics } & 5.0 & $1: 93$ & $78(35.5)$ & $1: 35$ & $186(32.7)$ & $1: 9$ & 419 (29.4) \\
\hline & 10.0 & $1: 143$ & $108(50.5)$ & $1: 51$ & $246(43.3)$ & $1: 12$ & $574(40.3)$ \\
\hline \multirow[t]{2}{*}{ MAP } & 5.0 & $1: 88$ & $125(58.4)$ & $1: 31$ & $250(44.0)$ & $1: 8$ & $532(37.3)$ \\
\hline & 10.0 & $1: 159$ & $156(72.9)$ & $1: 52$ & $337(59.3)$ & $1: 12$ & $763(53.5)$ \\
\hline \multirow[t]{2}{*}{ PAPP-A } & 5.0 & $1: 88$ & $93(43.6)$ & $1: 33$ & $212(37.3)$ & $1: 9$ & 449 (31.5) \\
\hline & 10.0 & $1: 151$ & $117(54.7)$ & $1: 52$ & $274(48.2)$ & $1: 12$ & $601(42.1)$ \\
\hline$\overline{\text { PLGF }}$ & 5.0 & $1: 95$ & $127(59.3)$ & $1: 33$ & $232(40.8)$ & $1: 9$ & $415(29.1)$ \\
\hline PAPP-A and PLGF & 10.0 & $1: 181$ & $159(74.3)$ & $1: 56$ & $317(55.8)$ & $1: 12$ & $582(40.8)$ \\
\hline \multirow[t]{2}{*}{ Uterine artery PI, MAP and PAPP-A } & 5.0 & $1: 105$ & $175(81.8)$ & $1: 26$ & $298(52.5)$ & $1: 7$ & $514(36.0)$ \\
\hline & 10.0 & $1: 216$ & $198(92.5)$ & $1: 65$ & $424(74.6)$ & $1: 12$ & $811(59.9)$ \\
\hline \multirow[t]{2}{*}{ Uterine artery PI, MAP and PLGF } & 5.0 & $1: 126$ & $187(87.4)$ & $1: 36$ & $344(60.6)$ & $1: 8$ & $536(37.6)$ \\
\hline & 10.0 & $1: 261$ & $205(95.8)$ & $1: 67$ & $439(77.3)$ & $1: 12$ & $755(52.9)$ \\
\hline \multirow[t]{2}{*}{ Uterine artery PI, MAP, PAPP-A and PLGF } & 5.0 & $1: 128$ & $200(93.4)$ & $1: 36$ & $347(61.1)$ & $1: 8$ & $539(37.8)$ \\
\hline & 10.0 & $1: 269$ & $206(96.3)$ & $1: 67$ & $435(76.6)$ & $1: 12$ & $764(53.6)$ \\
\hline
\end{tabular}

\section{Gestational Age at Delivery with PE Given Maternal} Characteristics

We have previously reported a Gaussian regression model for the gestational age at delivery of pregnancies with $\mathrm{PE}$ and the effect on this gestation of variables from maternal demographic characteristics, medical and obstetric history [9]. In this model, which assumes that if the pregnancy was to continue indefinitely all women would develop PE, the mean gestational age for delivery with PE was 55 weeks with an estimated SD of 7.11 weeks. Certain variables, including advancing maternal age over 30 years, increasing weight, Afro-Caribbean and South Asian racial origin, previous pregnancy with $\mathrm{PE}$, conception by in vitro fertilization and a medical history of chronic hypertension, type 2 diabetes mellitus and systemic lupus erythematosus or antiphospholipid syndrome increase the risk for development of PE. The consequence of this increased risk was a shift to the left of the Gaussian distribution of the gestational age at delivery with PE.

\section{Distribution of Biomarkers in Pregnancies with PE}

In pregnancies with $\mathrm{PE}$ there was an inverse correlation between MoM values of uterine artery PI and MAP with gestational age at delivery [9].

Similarly, there was a significant correlation between PAPP-A MoM and PLGF MoM with gestational age at delivery in PE (fig. 1, 2). The fitted regression models for $\log _{10}$ MoM values on gestational age at delivery are presented in table 1 and the estimated parameters for the assumed multivariate Gaussian distributions for log MoM values are given in table 2.

\section{Performance of Screening for PE}

Estimated detection rates of $\mathrm{PE}$ requiring delivery before 34,37 and 42 weeks' gestation, at false-positive rates of 5 and $10 \%$ in screening by maternal factors, uterine artery PI, MAP, serum PAPP-A, PLGF and their combination are given in table 3 .

Table 4 compares the expected and observed number of cases according to the estimated risk range. Table 5 shows the performance of screening for $\mathrm{PE}$ requiring delivery be- 
Table 4. Accuracy of estimated risk for PE by a combination of maternal characteristics, uterine artery PI, MAP, serum PAPP-A and serum PLGF (combined testing)

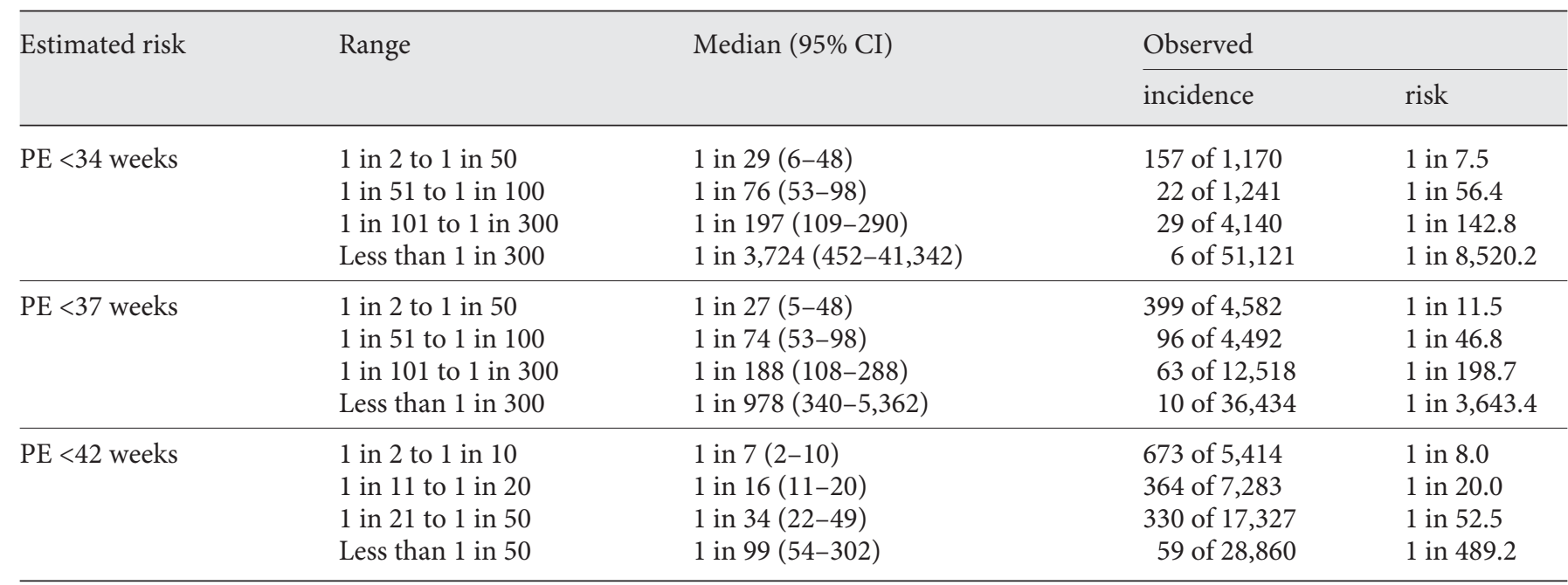

fore 37 weeks' gestation by maternal factors, uterine artery PI, MAP, serum PAPP-A and serum PLGF at a risk cutoff of 1:65 in women of Caucasian and Afro-Caribbean racial origin and according to obstetric history. In women of Afro-Caribbean racial origin compared to Caucasians, and in nulliparous compared to parous women, both the falsepositive rate and detection rates for $\mathrm{PE}$ are higher.

\section{Discussion}

This study has established a new approach for early screening for PE by a combination of maternal characteristics and history with biophysical and biochemical markers. In this approach, which is based on a survival time model, the gestation at the time of delivery for PE is treated as a continuous rather than categorical variable. As demonstrated by the MoM values of uterine artery PI, MAP and serum PAPP-A, and PLGF in pregnancies with $\mathrm{PE}$, the distribution with gestational age is linear. Consequently, PE could be considered as a single pathophysiological entity with a wide spectrum of severity manifested in gestational age at which delivery becomes necessary for maternal and/or fetal indications. The major advantage of the new model, compared to our previous models $[7,8]$, is that it offers the option to clinicians and researchers to select their own gestational age cutoff to define the high-risk group that could potentially benefit from therapeutic interventions starting from the first trimester of pregnancy [4-6].
Table 5. Estimated detection rates of PE requiring delivery before 37 weeks' gestation and false-positive rates, at a risk cutoff of 1:65 in screening by maternal factors, uterine artery PI, MAP, serum PAPP-A and serum PLGF according to Caucasian and Afro-Caribbean racial origin and obstetric history (\%)

\begin{tabular}{lrc}
\hline Study population & False-positive rate & Detection rate \\
\hline Total & $5,572 / 57,458(9.7)$ & $432 / 568(76.1)$ \\
Caucasian all & $3,012 / 42,514(7.1)$ & $181 / 281(64.4)$ \\
Caucasian nulliparous & $2,077 / 21,785(9.5)$ & $130 / 187(69.5)$ \\
Caucasian parous & $935 / 20,729(4.5)$ & $51 / 94(54.3)$ \\
Afro-Caribbean all & $2,007 / 9,268(21.7)$ & $200 / 224(89.3)$ \\
Afro-Caribbean nulliparous & $1,061 / 3,638(29.2)$ & $93 / 96(96.9)$ \\
Afro-Caribbean parous & $946 / 5,630(16.8)$ & $107 / 128(83.6)$
\end{tabular}

The data on maternal characteristics and the biophysical markers were reported previously [9] and the algorithm presented in this study incorporates the biochemical markers of serum PAPP-A and PLGF. In early biochemical screening for PE, several biochemical markers have been proposed, including maternal serum or plasma levels of soluble endoglin, inhibin-A, activin-A, pentraxin-3 and P-selectin, which are increased, and PAPP-A, PLGF and placental protein-13, which are decreased [1928]. These markers are thought to be involved in placentation or in the cascade of events leading from impaired placentation to development of clinical symptoms of PE. In this study we examined only PAPP-A and PLGF because these are the only two that have been investigated 
extensively in screening for PE; they have both been shown to be useful in screening for aneuploidies $[14,18]$ and they are now part of the platform of automated machines that provide reproducible results within 30-40 min of sampling.

The findings demonstrate that in first-trimester screening for PE, the performance of the test is better for early- rather than late-onset disease. This is particularly important because the objective of early screening is to identify the high-risk group that may benefit from therapeutic interventions that reduce the prevalence of PE. The prophylactic use of low-dose aspirin starting before 16 weeks' gestation is particularly effective in the prevention of preterm rather than term PE [5]. In screening for $\mathrm{PE}$ requiring delivery before 34 weeks, the detection rate, at a $10 \%$ false-positive rate, was about $50 \%$ by maternal characteristics, and this was improved to about $90 \%$ by the addition of biophysical markers and to about $75 \%$ by the addition of biochemical markers. The detection rate improved to more than $95 \%$ in screening by an algorithm combining maternal factors, biophysical markers and biochemical markers.
The new algorithm provides accurate patient-specific risks, and in each range of estimated risks for PE by combined screening there was in general good agreement between the expected and observed number of affected pregnancies. The false-positive rate and detection rates of $\mathrm{PE}$ are influenced by the characteristics of the study population, and for a given risk cutoff they are both higher in nulliparous than in parous women and in those of AfroCaribbean rather than Caucasian racial origin. Consequently, comparison of the performance of screening using these algorithms between studies requires the appropriate adjustments for the characteristics of the population under investigation.

\section{Acknowledgments}

The study was supported by a grant from The Fetal Medicine Foundation (UK Charity No. 1037116).

\section{References}

1 World Health Organization: Make Every Mother and Child Count. World Health Report, 2005. Geneva, World Health Organization, 2005.

2 Confidential Enquiry into Maternal and Child Health (CEMACH) Perinatal Mortality 2006: England, Wales and Northern Ireland. London, CEMACH, 2008.

3 Duley L: The global impact of pre-eclampsia and eclampsia. Semin Perinatol 2009;33: 130-137.

-4 Bujold E, Roberge S, Lacasse Y, Bureau M, Audibert F, Marcoux S, Forest JC, Giguere Y: Prevention of preeclampsia and intrauterine growth restriction with aspirin started in early pregnancy: a meta-analysis. Obstet $\mathrm{Gy}$ necol 2010;116:402-414.

5 Roberge S, Villa P, Nicolaides KH, Giguère Y, Vainio M, Bakthi A, Ebrashy A, Bujold E: Early administration of low dose aspirin for the prevention of preterm and term preeclampsia: a systematic review and metaanalysis. Fetal Diagn Ther 2012;31:141-146.

6 Nicolaides KH: Turning the pyramid of prenatal care. Fetal Diagn Ther 2011;29:183196.

-7 Poon LC, Kametas NA, Maiz N, Akolekar R, Nicolaides KH: First-trimester prediction of hypertensive disorders in pregnancy. Hypertension 2009;53:812-818.
-8 Akolekar R, Syngelaki A, Sarquis R, Zvanca M, Nicolaides KH: Prediction of early, intermediate and late pre-eclampsia from maternal factors, biophysical and biochemical markers at 11-13 weeks. Prenat Diagn 2011; 31:66-74.

9 Wright D, Akolekar R, Syngelaki A, Poon LCY, Nicolaides KH: A competing risks model in early screening for preeclampsia. Fetal Diagn Ther 2012; E-pub ahead of print; DOI: $10.1159 / 000338470$.

10 Kagan KO, Wright D, Valencia C, Maiz N, Nicolaides KH: Screening for trisomies 21, 18 and 13 by maternal age, fetal nuchal translucency, fetal heart rate, free beta-hCG and pregnancy-associated plasma protein-A. Hum Reprod 2008;23:1968-1975.

11 Robinson HP, Fleming JE: A critical evaluation of sonar crown rump length measurements. Br J Obstet Gynaecol 1975;82:702710.

12 Poon LC, Zymeri NA, Zamprakou A, Syngelaki A, Nicolaides KH: Protocol for measurement of mean arterial pressure at 11-13 weeks' gestation. Fetal Diagn Ther 2012;31: 42-48.

13 Plasencia W, Maiz N, Bonino S, Kaihura C, Nicolaides KH: Uterine artery Doppler at 11 +0 to $13+6$ weeks in the prediction of preeclampsia. Ultrasound Obstet Gynecol 2007; 30:742-749.
14 Pandya P, Wright D, Syngelaki A, Akolekar R, Nicolaides KH: Maternal serum placental growth factor in prospective screening for aneuploidies at 8-13 weeks' gestation. Fetal Diagn Ther 2012;31:87-93.

15 Brown MA, Lindheimer MD, de Swiet M, Van Assche A, Moutquin JM: The classification and diagnosis of the hypertensive disorders of pregnancy: statement from the International Society for the Study of Hypertension in Pregnancy (ISSHP). Hypertens Pregnancy 2001;20:IX-XIV.

16 Poon LCY, Volpe N, Muto B, Syngelaki A, Nicolaides KH: Birthweight with gestation and maternal characteristics in live births and stillbirths. Fetal Diagn Ther 2012; July 26; E-pub ahead of print;DOI: 10.1159/ 000338655

17 Kalbfleisch JD, Prentice RL: The Statistical Analysis of Failure Time Data, ed 2. New York, Wiley, 2002.

18 Wright D, Spencer K, Kagan KK, Tørring N, Petersen OB, Christou A, Kallikas J, Nicolaides KH: First-trimester combined screening for trisomy 21 at 7-14 weeks' gestation. Ultrasound Obstet Gynecol 2010;36:404411.

Akolekar/Syngelaki/Poon/Wright/ Nicolaides 
19 Foidart JM, Manuat C, Akolekar R, Cruz J, Nicolaides KH: Maternal plasma soluble endoglin at 11-13 weeks of pregnancy in preeclampsia. Ultrasound Obstet Gynecol 2010; 35:680-687.

20 Akolekar R, Minekawa R, Veduta A, Romero XC, Nicolaides KH: Maternal plasma inhibin $A$ at 11 to 13 weeks of gestation in hypertensive disorders of pregnancy. Prenat Diagn 2009;29:753-760.

-21 Akolekar R, Etchegaray A, Zhou Y, Maiz N, Nicolaides KH: Maternal serum activin A at 11 to 13 weeks of gestation in hypertensive disorders of pregnancy. Fetal Diagn Ther 2009;25:322-327.
22 Akolekar R, Casagrandi D, Livanos P, Tetteh A, Nicolaides KH: Maternal plasma pentraxin 3 at 11 to 13 weeks of gestation in hypertensive disorders of pregnancy. Prenat Diagn 2009;29:934-938.

23 Akolekar R, Veduta A, Minekawa R, Chelemen T, Nicolaides KH: Maternal plasma Pselectin at 11 to 13 weeks of gestation in hypertensive disorders of pregnancy. Hypertens Pregnancy 2011;30:311-321.

24 Poon LC, Maiz N, Valencia C, Plasencia W, Nicolaides KH: First-trimester maternal serum pregnancy-associated plasma protein-A and pre-eclampsia. Ultrasound Obstet Gynecol 2009;33:23-33.

25 Akolekar R, Zaragoza E, Poon LCY, Pepes S, Nicolaides KH: Maternal serum placental growth factor (PlGF) at 11 to 13 weeks of gestation in hypertensive disorders of pregnancy. Ultrasound Obstet Gynecol 2008;32:732739.
26 Akolekar R, Syngelaki A, Beta J, Kocylowski R, Nicolaides KH: Maternal serum placental protein 13 at 11-13 weeks of gestation in preeclampsia. Prenat Diagn 2009;29:1103-1108.

27 Silasi M, Cohen B, Karumanchi SA, Rana S: Abnormal placentation, angiogenic factors, and the pathogenesis of preeclampsia. Obstet Gynecol Clin North Am 2010;37:239-253.

28 Zhong Y, Tuuli M, Odibo AO: First-trimester assessment of placenta function and the prediction of preeclampsia and intrauterine growth restriction. Prenat Diagn 2010;30: 293-308. 


\section{Erratum}

In the paper by Akolekar R, Syngelaki A, Poon L, Wright D and Nicolaides KH, entitled 'Competing risks model in early screening for preeclampsia by biophysical and biochemical markers' [Fetal Diagn Ther 2013;33:8-15, DOI: 10.1159/000341264], the following amendment should be made:

Table 1. Fitted regression model for marker $\log _{10}$ MoM values on gestation at time of delivery for pregnancies with $\mathrm{PE}$

The intercept for PLGF should be a negative integer. Therefore, 0.861296 should be replaced by -0.861296 . 